\title{
FERMENTASI NATA DARI SARI BUAH KURMA (Phoenix dactylifera) TERHADAP BEBERAPA VARIASI KONSENTRASI STARTER Acetobacter xylinum
}

\author{
Amelia Rumi \\ Akademi Farmasi Tadulako Farma Palu \\ Email : amelia.rumi@gmail.com.
}

\begin{abstract}
It has conducted research on the utilization of kurma juice to several concentration variant starter Acetobacter xylinum, by measuring the thickness, weight, moisture content, ash content, and crude fiber content. Date palm juice which was added glacial acetic acid, potassium dihidrogen phosphate $600 \mathrm{mg}$, magnesium sulphate $600 \mathrm{mg}$, sugar $48 \mathrm{gram}$, and 6 gram of urea and incorporated into several containers of $100 \mathrm{ml}$ and varied the volume of the starter $5 \%, 10 \%$, and $20 \%$ of $14 \times 24$ hours fermented in $37{ }^{\circ} \mathrm{C}$ temperature. Results showed the concentration of $5 \%$ was obtained thickness $14 \mathrm{~mm}$, weight 30,7 gram, 81,75\% moisture content, ash content $0,10 \%$, and $3,93 \%$ crude fiber content, the concentration of $10 \%$ obtained thickness $16 \mathrm{~mm}$, weight $39,7 \mathrm{gram}, 85,44 \%$ moisture content, ash content $0,11 \%$, and $4,5 \%$ crude fiber content, the concentration of $20 \%$ obtained thickness $15 \mathrm{~mm}$, weight 32,5\%, 82,65\% moisture content, ash content $0,08 \%$, and $4,5 \%$ crude fiber content.
\end{abstract}

Keywords : Nata fermented, kurma juice, Acetobacter xylinum.

\section{PENDAHULUAN}

Buah kurma merupakan buah yang mengusung sejarah panjang anugerah dan menyebarkan banyak karunia di bidang ilmiah, ekonomi, dan kesehatan selama berabad-abad ini menduduki posisi yang istimewa di jantung kawasan Arab-Islam.

Dari beberapa eksperimen yang telah dilakukan membuktikan kandungan vitamin dan kalori kurma ternyata sangat tinggi, mengandung tanin, mengandung berbagai macam mineral yang diperlukan oleh tubuh seperti, kalium, kalsium, zat besi, mangan, sulfur, natrium, fosfor, dan magnesium. Rasulullah SAW juga merekomendasikan kurma sebagai obat bagi gangguan jantung, berdasarkan beberapa riwayat. IImu pengetahuan modern juga membuktikan bahwa kurma dapat mencegah gangguan sistem pernapasan, obat anti penuaan dini, memperlancar proses persalinan, memperkaya ASI, terapi untuk diabetes, obat kanker, ginjal dan hati. ${ }^{1}$ Inilah buah yang terus-menerus 
Fermentasi nata dari sari buah kurma (Phoenix dactylifera) terhadap beberapa variasi konsentrasi STARTER Acetobacter xylinum

menjadi materi kajian dan analisa para ilmuwan dan para peneliti, menjadi objek percobaan dan penelitian, dan menjadi pusat perhatian banyak negara setelah ia menjadi unsur penting dalam pembangunan ekonomi. Oleh karena itu, dalam penelitian ini digunakan kurma dengan cara fermentasi dalam pembuatan nata dengan memanfaatkan buah yang telah memiliki banyak keistimewaan tersebut. Mikroorganisme pada pembuatan nata dimana bakteri Acetobacter xylinum ditumbuhkan pada media dengan kadar gula yang tinggi pada sari buah kurma sehingga menghasilkan produk yang bermanfaat dan dapat digunakan dalam skala industri untuk menghasilkan berbagai macam zat kimia, enzim, asam amino, vitamin dan substansi lain yang dapat memberikan manfaat bagi tubuh.

\section{METODE PENELITIAN}

\section{Alat dan Bahan}

Alat yang digunakan dalam penelitian ini adalah autoklaf (Smic Model YX-280 B), batang pengaduk, blender, botol fermentasi, cawan porselin, corong, desikator, erlenmeyer $500 \mathrm{~mL}\left(\right.$ Pyrex $^{\circledR}$ ), gelas kimia $500 \mathrm{~mL}$ $\left(\right.$ Pyrex $\left.^{\circledR}\right)$, gelas arloji, gelas ukur 10 dan $50 \mathrm{~mL}\left(\right.$ Pyrex $\left.^{\circledR}\right)$, labu takar 100 dan $1000 \mathrm{~mL}\left(\right.$ Pyrex $\left.^{\circledR}\right)$, lampu spiritus, oven $\left(\right.$ Memmert $\left.^{\circledR}\right)$, pemanas listrik, pendingin liebig, pipet skala, pipet tetes, pipet volume $50 \mathrm{~mL}$ (Pyrex ${ }^{\circledR}$ ), saringan, sendok tanduk, statif dan klem, tangas air, tanur $\left(\right.$ Neycraft $\left.^{\circledR}\right)$, timbangan analitik $\left(\mathrm{Chyo}^{\circledR}{ }^{\circledR}\right.$.

Bahan dalam penelitian ini adalah aluminium foil, alkohol $96 \%$, akuades, asam asetat glasial, benang godam, buah kurma (Phoenix dactylifera), glukosa (gula), $\mathrm{H}_{2} \mathrm{SO}_{4}$, kain kasa, kertas $\mathrm{pH}$ universal, kertas timbang, pupuk ZA (urea), $\mathrm{K}_{2} \mathrm{HPO}_{4}$, $\mathrm{K}_{2} \mathrm{SO}_{4}, \mathrm{MgSO}_{4}, \mathrm{NaOH}$, n-hexan dan starter Acetobacter xylinum.

\section{Prosedur Penelitian}

\section{Pengambilan sampel}

Buah kurma

(Phoenix dactylifera) yang digunakan dibeli di pasar tradisional Ampel Surabaya (Jawa Timur) karena merupakan salah satu daerah terbesar tempat stok kurma yang terus-menerus ada. Kemudian dikeluarkan bijinya dan dicuci bersih lalu dihaluskan dengan cara diblender, disaring sampai ampasnya tidak terdapat dalam sari buah dan diambil sari buahnya untuk digunakan sebagai bahan baku pembuatan nata.

\section{Penyiapan Alat-alat}

Alat-alat yang digunakan dicuci hingga bersih dengan air suling, 
Fermentasi nata dari sari buah kurma (Phoenix dactylifera) terhadap beberapa variasi konsentrasi STARTER Acetobacter xylinum

kemudian alat-alat gelas dikeringkan lalu dibungkus dengan kertas dan disterilkan dengan menggunakan oven pada suhu $180^{\circ} \mathrm{C}$ selama 2 jam. Alatalat gelas yang berskala dan tidak tahan terhadap pemanasan dan yang terbuat dari plastik disterilkan dalam autoklaf pada suhu $121^{\circ} \mathrm{C}$ dengan tekanan 2 atm selama 15 menit.

\section{Pembuatan Larutan}

1. Larutan $\mathrm{H}_{2} \mathrm{SO}_{4} 1,25 \%$ : $\mathrm{H}_{2} \mathrm{SO}_{4} 12,5$ $\mathrm{mL}$ diencerkan dengan akuades dalam labu takar $1000 \mathrm{~mL}$ sampai garis tanda lalu dihomogenkan.

2. Larutan $\mathrm{NaOH} 1,25 \%$ : $\mathrm{NaOH} 12,5$ $\mathrm{g}$ dilarutkan dengan akuades dalam labu takar $1000 \mathrm{~mL}$ sampai garis tanda lalu dihomogenkan.

3. Larutan $\mathrm{K}_{2} \mathrm{SO}_{4} 10 \%: \mathrm{K}_{2} \mathrm{SO}_{4} 10 \mathrm{~g}$ dilarutkan dengan akuades dalam labu takar $100 \mathrm{~mL}$ sampai garis tanda lalu dihomogenkan.

\section{Pembuatan Nata}

Pertama-tama buah kurma dikeluarkan dari bijinya, dicuci hingga bersih lalu diblender dengan air sedikit demi sedikit hingga halus (memakai perbandingan $100 \mathrm{~g}$ buah kurma tanpa biji dalam $600 \mathrm{~mL}$ air). Kemudian buah kurma yang telah halus disaring dengan kain kasa atau saringan sampai ampasnya tidak terdapat lagi dalam sari buah. Diambil sari kurma yang telah disaring sebanyak $300 \mathrm{~mL}$ dan dipanaskan hingga mendidih sambil diaduk. Kemudian ditambahkan gula pasir $24 \mathrm{~g}$ lalu ditambahkan $\mathrm{K}_{2} \mathrm{HPO}_{4} 300 \mathrm{mg}, \mathrm{MgSO}_{4} 300 \mathrm{mg}$ sambil terus menerus diaduk. Jika ada kotoran dipermukaan larutan dibersihkan (dibuang). Setelah mendidih selama 15 menit, larutan diangkat kemudian didinginkan. Setelah dingin, ditambahkan urea sebanyak $3 \mathrm{~g}$ dan asam asetat secukupnya ( $\mathrm{pH}$ campuran $3-4$ ). Sari buah kurma kemudian dituang ke dalam 3 wadah, dimana pada wadah I berisi $95 \mathrm{~mL}$, wadah II berisi $90 \mathrm{~mL}$, dan wadah III berisi $80 \mathrm{~mL}$ sari buah kurma. Kemudian, pada masing masing wadah ditambahkan starter Acetobacter xylinum dengan konsentrasi sebanyak $5 \%, 10 \%$, dan $20 \%$. Langkah terakhir yaitu wadah ditutup dengan menggunakan kain kasa dan diikat dengan karet hingga benar - benar rapat. Disimpan selama 14x24 jam di dalam ruang fermentasi. Setelah itu nata yang terbentuk dicuci dengan air bersih atau direndam dengan air mengalir sampai rasa asamnya hilang atau pHnya netral. Kemudian nata dipotong-potong dengan ukuran 1-1,5 cm. potongan nata dicuci dan direbus selama 5-10 menit. Hal ini diulangi sampai nata 
Fermentasi nata dari sari buah kurma (Phoenix dactylifera) terhadap beberapa variasi konsentrasi STARTER Acetobacter xylinum

tidak berbau dan tidak berasa asam lagi.

\section{Penentuan Kadar Air}

Nata sebanyak $2 \mathrm{~g}$ ditimbang dalam gelas arloji yang telah diketahui beratnya kemudian dikeringkan dalam oven pada suhu $100-105^{\circ} \mathrm{C}$ selama 6 jam, didinginkan didalam desikator selama 20 menit. Setelah dingin ditimbang berat keringnya. Penimbangan diulangi sampai diperoleh berat yang konstan.

\section{Penentuan Kadar Abu secara} Gravimetri

Nata sebanyak 2 g ditimbang dalam cawan porselin yang telah diketahui beratnya, kemudian diabukan dengan api kecil hingga semua menjadi arang. Selanjutnya, dibakar dalam tanur pengabuan pada suhu $500^{\circ} \mathrm{C}$ selama 5 jam sampai diperoleh abu berwarna keputihputihan. Didinginkan didalam desikator kemudian ditimbang dan penimbangan diulangi sampai diperoleh berat yang konstan.

\section{Penentuan Kadar Serat Kasar dengan Metode Defatting dan Digestion}

Nata sebanyak $2 \mathrm{~g}$ dimasukkan kedalam gelas erlenmeyer kemudian dikeringkan pada suhu $110^{\circ} \mathrm{C}$ dan dihaluskan. Ditambahkan alkohol 96\% sebanyak $50 \mathrm{~mL}$ dan diuapkan, ditambahkan $50 \mathrm{~mL}$ n-heksan dan direfluks selama 30 menit kemudian disaring dan ditambahkan $200 \mathrm{~mL}$ $\mathrm{H}_{2} \mathrm{SO}_{4} \quad 1,25 \%$ kedalam residu. Selanjutnya, gelas erlenmeyer dipasang pada pendingin liebig lalu dididihkan selama 30 menit. Kemudian disaring dengan kertas saring dan residunya dicuci dengan akuades panas. Residu dipindahkan kedalam gelas erlenmeyer, sisanya dicuci dengan $200 \mathrm{~mL} \mathrm{NaOH} \mathrm{1,25 \%} \mathrm{sampai}$ semua residu masuk kedalam gelas erlenmeyer kemudian dididihkan lagi selama 30 menit dan disaring dengan kertas saring yang telah diketahui beratnya. Residu dicuci dengan menggunakan $\mathrm{K}_{2} \mathrm{SO}_{4} \quad 10 \%$ lalu dicuci lagi dengan akuades panas dan dengan alkohol 96\%. Kertas saring dikeringkan dalam oven pada suhu $110^{\circ} \mathrm{C}$ kemudian didinginkan dalam desikator lalu diabukan dalam tanur pada suhu $550^{\circ} \mathrm{C}$ dan selanjutnya didinginkan dalam desikator dan dilakukan penimbangan sampai diperoleh berat yang konstan. 
Fermentasi nata dari sari buah kurma (Phoenix dactylifera) terhadap beberapa variasi konsentrasi STARTER $\underline{\text { Acetobacter xylinum }}$

\section{HASIL PENELITIAN}

\section{Ketebalan Nata}

Tabel 1. Pengaruh Ketebalan Nata Berdasarkan Waktu Fermentasi.

\begin{tabular}{cccc}
\hline Hari Pengamatan & $\begin{array}{c}\text { Starter } \mathbf{5 \%} \\
\text { Tebal }(\mathbf{m m})\end{array}$ & $\begin{array}{c}\text { Starter } \mathbf{1 0 \%} \\
\text { Tebal }(\mathbf{m m})\end{array}$ & $\begin{array}{c}\text { Starter } \mathbf{2 0} \% \\
\text { Tebal }(\mathbf{m m})\end{array}$ \\
\hline Hari ke-1 & 0 & 0 & 0 \\
Hari ke-2 & 0 & 0 & 0 \\
Hari ke-3 & 0 & 0 & 0 \\
Hari ke-4 & 0 & 0 & 0 \\
Hari ke-5 & 0 & 1 & 2 \\
Hari ke-6 & 1 & 2 & 3 \\
Hari ke-7 & 3 & 5 & 5 \\
Hari ke-8 & 8 & 10 & 9 \\
Hari ke-9 & 11 & 11 & 11 \\
Hari ke-10 & 12 & 12 & 14 \\
Hari ke-11 & 13 & 13 & 14 \\
Hari ke-12 & 13 & 15 & 14 \\
Hari ke-13 & 14 & 16 & 15 \\
Hari ke-14 & 14 & & 15 \\
\hline
\end{tabular}

\section{Berat Nata}

Tabel 2. Data Hasil Pengukuran Berat Nata

\begin{tabular}{cc}
\hline Perlakuan & Berat (gram) \\
\hline Starter 5\% & 30,7 \\
Starter 10\% & 39,7 \\
Starter 20\% & 32,5 \\
\hline
\end{tabular}

\section{Kadar Air}

Tabel 3. Data Hasil Pengukuran Kadar Air Nata (\%)

\begin{tabular}{rc}
\hline Perlakuan & $\%$ \\
\hline Starter 5\% & 81,75 \\
Starter 10\% & 85,44 \\
Starter 20\% & 82,65 \\
\hline
\end{tabular}

\section{Kadar Abu}

Tabel 4. Data Hasil Pengukuran Kadar Abu (\%)

\begin{tabular}{cc}
\hline Perlakuan & $\%$ \\
\hline Starter 5\% & 0,10 \\
Starter $10 \%$ & 0,11 \\
Starter $20 \%$ & 0,08 \\
\hline
\end{tabular}

\section{Kadar Serat Kasar}

Tabel 5. Data Hasil Pengukuran Kadar Serat Kasar (\%)

\begin{tabular}{cc}
\hline Perlakuan & $\%$ \\
\hline Starter $5 \%$ & 3,93 \\
\hline
\end{tabular}


Fermentasi nata dari sari buah kurma (Phoenix dactylifera) terhadap beberapa variasi konsentrasi STARTER Acetobacter xylinum

PEMBAHASAN

\section{Ketebalan Nata}

Ketebalan nata merupakan
hasil metabolisme Acetobacter
xylinum. Selulosa yang dihasilkan
Acetobacter xylinum terus berikatan
satu dengan yang lainnya hingga
membentuk lapisan yang terus
menebal.

Hasni $\quad(2010)^{2} \quad$ dalam

penelitiannya menjelaskan bahwa produksi nata dari sari buah gandaria (Bouea macrophylla) dengan menggunakan variasi konsentrasi starter, didapatkan waktu awal pertumbuhan nata yaitu pada hari keempat dengan tebal $5 \mathrm{~mm}$ dan hari keempat belas dengan tebal $20 \mathrm{~mm}$ pada konsentrasi $10 \%$ dan pada Hastuti (2010) melaporkan bahwa produksi nata dari sari buah anggur (Vitis vinifera) dengan variasi konsentrasi starter Acetobacter xylinum didapatkan waktu awal pertumbuhan nata pada hari keempat dengan tebal $2 \mathrm{~mm}$ dan hari keempat belas dengan tebal $21 \mathrm{~cm}^{5}$ Dibandingkan dengan kedua peneliti sebelumnya, waktu awal fermentasi nata dari buah kurma (Phoenix dactylifera) lebih lambat yaitu pada hari kelima. Mungkin itu dapat disebabkan kandungan gula dalam buah kurma kadarnya bisa mencapai
$32 \%{ }^{1}$ dan pada penelitan ini buah kurma (Phoenix dactylifera) diblender dengan menambahkan air sedikit demi sedikit dengan memakai pengenceran 1:6 yang berarti 100 gram buah kurma (Phoenix dactylifera) dalam $600 \mathrm{~mL}$ air. Pada pengenceran $1: 6$, nata yang dihasilkan tumbuh dengan baik pada semua variasi konsentrasi starter dan hasilnya dapat dilihat pada (Tabel 1) dan konsistensi atau mutu nata yang dihasilkan tersebut agak rapat dan tebal, dikarenakan bakteri Acetobacter xylinum cukup efektif membentuk benang-benang selulosa pada sari buah kurma (Phoenix dactylifera). Sedangkan, nata berkualitas rendah teksturnya lembek, tipis dan berlubang-lubang ${ }^{3}$ karena bakteri Acetobacter xylinum tidak cukup banyak membentuk benang-benang selulosa.

\section{Berat Nata}

Berat nata dari sari buah kurma (Phoenix dactylifera) tertinggi dihasilkan pada konsentrasi starter 10 $\%$ dibandingkan konsentrasi $20 \%$ (Tabel 2) padahal jika dibandingkan dengan penelitian sebelumnya oleh Hastuti (2010) melaporkan bahwa produksi nata dari sari buah anggur (Vitis vinifera) dengan variasi konsentrasi starter Acetobacter 
Fermentasi nata dari sari buah kurma (Phoenix dactylifera) terhadap beberapa variasi konsentrasi STARTER Acetobacter xylinum

xylinum, berat nata tertinggi dihasilkan pada konsentrasi starter $15 \%$ dengan berat 38,96 gram. ${ }^{5}$ Fajriani (2010) melaporkan bahwa produksi nata dari sari buah siwalan (Borrassus flabellifer) dengan variasi konsentrasi Acetobacter xylinum, berat nata tertinggi dihasilkan pada konsentrasi starter $15 \%$ dengan berat 1,5254 gram dan Hasni (2010) melaporkan bahwa produksi nata dari sari buah gandaria (Bouea macrophylla) dengan menggunakan variasi konsentrasi starter, berat nata tertinggi dihasilkan pada konsentrasi starter $10 \%$ dengan berat $8000 \mathrm{mg}^{2,4} \mathrm{pH}$ medium dari sari buah kurma (Phoenix dactylifera) adalah 4,5 sesuai dengan kebutuhan Acetobacter xylinum untuk menjalin selulosa pada konsentrasi starter $10 \% .^{2,4}$

\section{Kadar Air}

Telah diketahui belum ada standar SNI mengenai kadar air yang harus dimiliki oleh nata. Pada (Tabel 3) dapat dilihat kadar air tertinggi dari nata sari buah kurma (Phoenix dactylifera) dihasilkan pada konsentrasi 10\%. Kadar air juga berhubungan dengan ketebalan yang dihasilkan lebih tinggi dibandingkan pada konsentrasi starter $5 \%$ tidak berbeda nyata kadar air dan ketebalannya dengan konsentrasi starter $20 \%$ (Tabel 3).

\section{Kadar Abu}

Abu adalah zat anorganik sisa hasil pembakaran suatu bahan organik. ${ }^{6}$ Menurut tabel syarat mutu nata SNI, bobot asing yang dikandung oleh nata harus tidak ada yakni zat-zat anorganik. Kadar abu yang terdapat dalam nata sari buah kurma (Phoenix dactylifera) pada konsentrasi $5 \%, 10$ $\%$, dan $10 \%$ tidak berbeda nyata (Tabel 4) dan sesuai dengan syarat mutu nata SNI.

Penelitian sebelumnya, Emma (2009) pernah melaporkan, pengaruh media starter antara air kelapa dan nira aren terhadap kualitas nata de arenga, bahwasanya kadar abu nata de arenga dengan menggunakan media fermentasi nira aren bergula dengan starter nira aren bergula (sampel 1) yaitu 0,324 mengalami peningkatan dibandingkan dengan nata dengan menggunakan media fermentasi nira aren tanpa gula (Sampel 4) yaitu 0,160. ${ }^{6}$ Dibandingkan dengan peneliti sebelumnya, kadar abu nata dari sari buah kurma (Phoenix dactylifera) masih lebih rendah.

\section{Kadar Serat Kasar}

Serat kasar merupakan hasil perombakan gula pada medium 
Fermentasi nata dari sari buah kurma (Phoenix dactylifera) terhadap beberapa variasi konsentrasi STARTER Acetobacter xylinum

fermentasi oleh aktivitas Acetobacter xylinum. Acetobacter xylinum mengambil glukosa dari larutan gula, kemudian digabungkan dengan asam lemak membentuk prekursor pada membran sel. Prekursor ini keluar bersama-sama enzim yang mempolimerisasikan glukosa menjadi selulosa diluar sel. Prekursor dari polisakarida tersebut adalah GDPglukosa. Kemampuan Acetobacter xylinum membentuk serat dipengaruhi oleh $\mathrm{pH}$ medium. Nilai $\mathrm{pH}$ yang makin rendah akan meningkatkan kemampuan Acetobacter xylinum dalam membentuk serat. ${ }^{7}$

Serat kasar atau Crude Fiber yang dihasilkan oleh nata dari sari buah kurma (Phoenix dactylifera) tertinggi dihasilkan oleh konsentrasi starter $10 \%$ (Tabel 5) dan pada konsentrasi starter $5 \%$ dan $20 \%$ kadar serat kasar yang dihasilkan tidak berbeda nyata. Hal ini disebabkan kerja bakteri Acetobacter xylinum lebih optimum pada konsentrasi starter 10 $\%$ untuk menghasilkan serat lebih besar. Syarat mutu nata terhadap serat makanan yang terkandung dalam nata menurut tabel $\mathrm{SNI}$ yaitu maks. $4,5 \%$ dan semua konsentrasi starter sesuai dengan tabel syarat mutu SNI.

\section{KESIMPULAN}

Dari hasil penelitian yang dilakukan dapat disimpulkan bahwa:

1. Sari buah kurma (Phoenix dactylifera) dapat dijadikan nata.

2. Nata yang lebih baik diproduksi Acetobacter xylinum pada konsentrasi $10 \%$ dengan memiliki ketebalan $16 \mathrm{~mm}$ dengan berat 39,7 gram.

3. Kadar air dan kadar abu tertinggi dihasilkan pada konsentrasi starter 10\% dimana kadar air yang dihasilkan sebesar $85,44 \%$ dan kadar abu sebesar $0,11 \%$ dan sesuai dengan syarat mutu nata SNI.

4. Kadar serat tertinggi diperoleh pada konsentrasi starter $10 \%$ sebesar 4,5\% dan semua konsentrasi starter sesuai dengan tabel syarat mutu SNI.

\section{DAFTAR PUSTAKA}

1. Ahmad. 'The Miracle of Dates' Rahasia Sehat Alami dengan Kurma. Depok: Penerbit Pustaka IIMan dan Penerbit Hikmah, 2008.

2. Hasni S. Produksi Nata dari Sari Buah Gandaria (Bouea macrophylla) dengan menggunakan Variasi Konsentrasi Starter (skripsi). Makassar: Fakultas Farmasi Universitas Muslim Indonesia, 2010.

3. Kartika, Bambang dkk. Pedoman Uji Inderawi Bahan Pangan. 1988. 
Fermentasi nata dari sari buah kurma (Phoenix dactylifera) terhadap beberapa variasi konsentrasi STARTER Acetobacter xylinum

4. Fajriani S. Produksi Nata dari Sari Buah Siwalan (Borrassus flabellifer) dengan menggunakan Variasi Konsentrasi Acetobacter xylinum (skripsi). Makassar: Fakultas Farmasi UMI, 2010.

5. Hastuti T. Produksi Nata dari Sari Buah Anggur (Vitis vinifera) dengan menggunakan Variasi Konsentrasi Acetobacter xylinum (skripsi). Makassar: Fakultas Farmasi Universitas Muslim Indonesia, 2010.
6. Emma S. Pengaruh Media Starter antara Air kelapa dan Nira Aren terhadap Kualitas Nata de Arenga (skripsi). Medan: FMIPA, Un iversitas Sumatera Utara., 2009.

7. Anastasia, N, dan Afrianto, $\mathrm{E}$, 2008. Mutu Nata de Seaweed dalam berbagai Konsentrasi Sari Jeruk Nipis. Prosiding Seminar Nasional Sains dan Teknologi II. Universitas Lampung. 